\title{
PERBANDINGAN ESTIMASI CURAH HUJAN MRR DAN TRMM B342 SEBAGAI INPUT MODEL HIDROLOGI HBV STUDI KASUS DAS BEDADUNG
}

\author{
Muhamad Zulvi Alhamda ${ }^{* 1}$, Entin Hidayah² dan Wiwik Yunarni ${ }^{2}$ \\ 1Mahasiswa / S1 Teknik Sipil, Fakultas Teknik / Jurusan Teknik Sipil / Universitas \\ Jember \\ 2 Dosen , Jabatan / Program Studi, Departemen / Jurusan, Instansi / Universitas \\ Korespondensi: entin.teknik@ unej.ac.id, zulvimuhammad@gmail.com
}

\begin{abstract}
The limitations of spatial and temporal distribution of rain gauge networks causes inaccuracies in prediction of hydrological modeling. The availability of satellite rain data products is a potential to overcome this limitation. This studies objective is to compare the quality of rain data from the recording of the Manual Rainfall Recorder (MRR) with satellite data TRMM B342 which is entered in the HBV hydrological modeling. Calibration results shows that HBV modeling performance with MRR rain data input is better than TRMM. $R^{2}$ and NSE values from MRR rain data input were 0.7153 and 0.7133 respectively with a mean error of 89 (mm / year). While the $R^{2}$ and NSE values of the TRMM B342 satellite rain data input were 0.57 and 0.55 with a mean error of 305 ( $\mathrm{mm} /$ year), respectively.
\end{abstract}

Keywords : DAS Bedadung, Model HBV, Pemodelan Hidrologi, Satelit TRMM.

\section{PENDAHULUAN}

Hujan sangat penting bagi sektor publik yang berhubungan dengan sumber daya air dan mitigasi bencana alam. Dalam perencanaan suatu waduk, irigasi, embung dan infrastruktur air lainnya memerlukan curah hujan sebagai salah satu data inputnya. Untuk menganalisis dan memprediksi hujan kendala yang sering ditemui adalah ketersediaan data hujan yang kurang memadai. Kendala berupa data series yang tidak lengkap maupun sebaran stasiun hujan yang tidak merata membuat tingkat akurasi pemodelan hidrologi menjadi kurang akurat. Adanya kendala-kendala tersebut membuat diperlukannya alternatif lain untuk mengatasi permasalahan yang berkaitan dengan ketersediaan data observasi. Salah satu dari beberapa alternatif tersebut adalah dengan menggunakan data satelit TRMM sebagai pengganti data hujan MRR untuk daerah yang memiliki sedikit rekaman pengamatan curah hujan permukaan. Data curah hujan satelit TRMM menyediakan data presipitasi secara spasial dengan resolusi tertentu. Dengan adanya data satelit TRMM 3B42 diharapkan dapat memprediksi besaran curah hujan pada daerahdaerah yang tidak tersedia pos stasiun hujan.

NASA (National Aeronautics and Space Administration) telah mengembangkan teknologi pendugaan besaran presipitasi suatu luasan melalui teknologi remote sensing. Dengan diluncurkannya satelit TRMM (Tropical Rainfall Measuring Mission) maka dapat diketahui besaran presipitasi dengan ragam resolusi spasial dan temporal. Terdapat 2 jenis data harian TRMM yang tersedia pada database NASA yaitu 3B42RT dan 3B42. Data 3B42 menyediakan jenis data yang memiliki pendugaan yang lebih akurat dan dapat dilakukan penelitian lanjutan terhadap data tersebut [1]. Sedangkan untuk 3B42RT menyediakan data pendugaan presipitasi yang kurang akurat namun cepat tersedia, cocok digunakan untuk kegiatan monitoring [1]. Data satelit TRMM ini telah diteliti penggunannya dalam 3 pola hujan yang berbeda di wilayah Indonesia. Validasi data satelit TRMM telah dilakukan dengan menggunakan resolusi 
temporal bulanan terhadap 3 pola hujan yang berbeda dan menunjukkan hasil yang baik pada wilayah dengan pola hujan monsun serta hasil yang cukup baik pada wilayah dengan pola hujan ekuatorial dan lokal [2].

Karakteristik Daerah Aliran Sungai (DAS) Bedadung, yang juga dimiliki DAS lainnya, memiliki variable yang beragam secara spasial dan temporal. Keragaman ini dicoba untuk dipahami melalui suatu pemodelan untuk memahami pengaruh dari setiap komponen yang ada. Dalam pengintegrasian informasi komponen dalam suatu DAS dapat dilakukan dengan pendekatan analisis sistem dalam kajian hidrologi DAS menjadi model-model hidrologi DAS [3]. Model hidrologi merupakan penyederhanaan menjadi konsep numerik dari suatu sistem hidrologi. Model-model ini memahami respon dari suatu DAS terhadap berbagai masukan DAS. Dengan adanya pemodelan hidrologi diharapkan dapat dilakukan prediksi respon dari suatu DAS apabila terjadi perubahan dari berbagai data masukan DAS.

Model HBV (Hydrologiska Byrans Vattenbalansavdelning) merupakan model rainfall-runoff yang mencakup konsep numerik dari proses hidrologi pada skala DAS. [4]. Model ini telah banyak dikembangkan antara lain HBV-ETH (Renner dan Braun 1990). HBV96 [5] dan HBV-Light (Seibert, 2005). Data input untuk HBV model adalah curah hujan, suhu udara dan perkiraan evapotranspirasi potensial. Periode waktu catatan data observasi yang digunakan adalah dalam skala harian. Namun direkomendasikan untuk menggunakan jangka waktu yang lebih pendek. Nilai penguapan yang digunakan biasanya menggunakan rata- rata bulanan walaupun dimungkinkan untuk menggunakan data harian. Data suhu udara juga digunakan untuk perhitungan akumulasi lelehan salju, yakni apabila data suhu melebihi temperature threshold dari snowpack maka akan dilakukan perhitungan akumulasi runoff yang berasal dari lelehan salju. Jika tidak ada, opsi terakhir yang digunakan adalah suhu dapat dihilangkan di area bebas salju.

Tujuan dari penelitian ini menggunakan model HBV untuk menilai kinerja dan keterbatasan produk curah hujan satelit TRMM resolusi tinggi yang canggih yang tersedia di Indonesia di daerah aliran sungai, Bedadung. DAS Bedadung memiliki pencatatan data debit yang bagus dan jaringan stasiun pengamatan curah hujan darat MMR yang terdistribusi dengan baik di bagian tegah DAS, tetapi pada bagian hulu DAS data catatan hujan harian darat yang kurang memadai.

\section{METODE PENELITIAN}

\subsection{Lokasi Penelitian}

Lokasi penelitan terletak pada DAS Bedadung yang berlokasi di Kabupaten Jember. DAS Bedadung memiliki letak geografis pada koordinat $113^{\circ} 35^{\prime}$ BT - 114 ${ }^{\circ} 1^{\prime} 17^{\prime \prime}$ BT dan $7^{\circ} 58^{\prime} 8^{\prime \prime}$ LS - $8^{\circ} 13^{\prime} 52^{\prime \prime}$ LS. DAS Bedadung memiliki sungai sepanjang $161 \mathrm{~km}$ dengan luas DAS seluas $645 \mathrm{~km}^{2}$. Sungai Bedadung memiliki hulu di wilayah lereng barat Pegunungan Hyang di sekitar Desa Rowosari, Kecamatan Sumberjambe dan bermuara ke Samudra Hindia di Kecamatan Puger. Lokasi DAS Bedadung dapat dilihat pada Gambar 1. Tanda lokasi berwarna merah menunjukkan lokasi outlet pengukuran debit stasiun AWLR Rawatamtu sebagai sumber data acuan pada proses kalibrasi debit model dengan debit observasi.

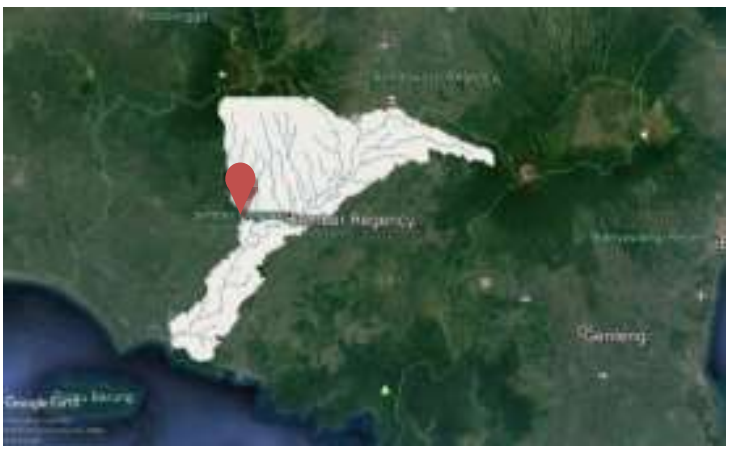

Gambar 1. Lokasi DAS Bedadung Kabupaten Jember

\subsection{Data dan Teknik Pengumpulan Data}

Data curah hujan MRR yang digunakan pada penelitian ini merupakan data sekunder dari 14 pos titik stasiun hujan yang diperoleh dari UPT PSDA Lumajang. Data yang digunakan sebagai input model diantaranya adalah curah hujan $(\mathrm{mm})$, suhu $\left(\mathrm{C}^{\circ}\right)$, debit $\left(\mathrm{m}^{3} / \mathrm{det}\right)$, dan evapotranspirasi $(\mathrm{mm})$. Periode data yang digunakan adalah data antara tahun 2008-2017. Pembagian periode kalibrasi dan validasi yaitu tahun 2008-2012 untuk periode kalibrasi sedangkan tahun 2013-2017 digunakan untuk periode validasi. Untuk data evapotranspirasi diperoleh dari perhitungan nilai 
evapotranspirasi potensial menggunakan Metode Pennman-Monteith. Data yang dibutuhkan dalam perhitungan evapotranspirasi diantaranya adalah kelembaban udara (\%), suhu $\left({ }^{\circ} \mathrm{C}\right)$, kecepatan angin $(\mathrm{km} / \mathrm{jam})$, dan radiasi matahari (\%). Selanjutnya terdapat data Digital Elevation Model (DEM) yang digunakan untuk mengetahui aspek spasial dari DAS Bedadung. Data yang digunakan adalah DEMNAS yang dapat diperoleh dari BIG (Badan Informasi Geospasial).

\subsection{Metode Analisis Data}

\subsubsection{Uji RAPS (Rescaled Adjusted Partial Sums)}

Data observasi yang didapatkan merupakan gambaran dari apa yang ada di lapangan. Agar data dapat merepresentasikan fenomena yang sebernarnya, keabsahan dari sebuah data perlu di uji ulang agar terhindar dari kesalahan-kesalahan. Berbeda dengan kurva massa ganda yang membandingan kualitas suatu data dengan data lainnya. RAPS ini menguji data dengan data itu sendiri dengan menghitung nilai kumulatif penyimpangannya terhadap nilai rata-rata. Berikut merupakan persamaanpersamaan yang digunakan dalam uji RAPS (Harto, 2009):

$$
\begin{array}{ll}
\mathrm{S}^{*} \mathrm{k} & =(Y i-Y) \\
\mathrm{S} * * \mathrm{k} & =S^{* k} / D y^{2} \\
\mathrm{Dy}^{2} & =\frac{\sum_{i}^{k}(Y i-Y)^{2}}{n}
\end{array}
$$

Dengan $\mathrm{k}=1,2,3, \ldots, \mathrm{n}, \mathrm{S} * \mathrm{k}=$ simpangan mutlak, $\mathrm{S}^{* *} \mathrm{k}=$ nilai konsistensi data, $\mathrm{n}=$ jumlah data, dan $\mathrm{Dy}=$ simpangan rata-rata. Nilai statistic data diuji dengan menentukan nilai $\mathrm{Q}$ dan R. Q = nilai maksimum $\left|\mathrm{S}^{* *} \mathrm{k}\right|$ untuk $0 \leq \mathrm{k} \leq$ $\mathrm{n}$, dan $\mathrm{R}=$ nilai maksimum $\mathrm{S} * * \mathrm{k}$ - nilai minimum $\mathrm{S}^{* *} \mathrm{k}$. Setelah nilai $\mathrm{Q}$ dan $\mathrm{R}$ diketahui maka dapat dicari nilai dari $\mathrm{Q} / \sqrt{n}$ dan $\mathrm{R} / \sqrt{n}$. Nilai tersebut berguna untuk justifikasi kualitas data dengan membandingkannya dengan tabel RAPS yang dapat dilihat pada Tabel 1, dan apabila memiliki nilai yang lebih rendah, maka data berada pada batasan konsisten.

Tabel.1 Nilai Uji RAPS

\begin{tabular}{ccccccc}
\hline & \multicolumn{3}{c}{$\mathbf{Q} / \sqrt{n}$} & \multicolumn{3}{c}{$\mathbf{R} / \sqrt{n}$} \\
\cline { 2 - 7 }$n$ & $\mathbf{9 0}$ & $\mathbf{9 5}$ & $\mathbf{9 9}$ & $\mathbf{9 0}$ & $\mathbf{9 5}$ & $\mathbf{9 9}$ \\
& $\mathbf{\%}$ & $\mathbf{\%}$ & $\mathbf{\%}$ & $\mathbf{\%}$ & $\mathbf{\%}$ & $\mathbf{\%}$ \\
\hline 10 & 1.05 & 1.14 & 1.29 & 1.21 & 1.28 & 1.38 \\
20 & 1.10 & 1.22 & 1.42 & 1.34 & 1.43 & 1.60 \\
\hline
\end{tabular}

\begin{tabular}{ccccccc}
\hline 30 & 1.12 & 1.24 & 1.46 & 1.40 & 1.50 & 1.70 \\
40 & 1.13 & 1.26 & 1.50 & 1.42 & 1.53 & 1.74 \\
50 & 1.14 & 1.27 & 1.52 & 1.44 & 1.55 & 1.78 \\
100 & 1.17 & 1.29 & 1.55 & 1.50 & 1.62 & 1.86 \\
$>10$ & 1.22 & 1.36 & 1.63 & 1.62 & 1.75 & 2.00 \\
0 & & & & & & \\
\hline
\end{tabular}

\subsubsection{Uji Korelasi Data Satelit TRMM 3B42}

Dalam penggunaan data satelit TRMM 3B42 perlu dilakukan validasi dengan data hujan MRR untuk mengetahui hubungan kesesuaian antara kedua data tersebut. Data satelit TRMM 3B42 diperoleh dari laman http://mirador.gsfc.nasa.gov dengan ekstensi netCDF. Jenis data TRMM yang digunakan pada penelitian ini adalah 3B42 yang memiliki resolusi spasial $0.25^{\circ} \times 0.25^{\circ}$ dan resolusi temporal harian. Selanjutnya data curah hujan dapat diekstrak dari file tersebut menggunakan aplikasi Panoply. Proses validasi dilakukan dengan dilakukannya analisis statistik menggunakan koefisien korelasi (r) dan RMSE (Root Mean Squared Error). Rumus dari koefisien korelasi dapat dinyatakan sebagai berikut:

$\mathrm{R}=\frac{n \sum x y-\sum x \sum y}{\sqrt{n \sum x^{2}-\left(\sum x\right)^{2}} \sqrt{n \sum y^{2}-\left(\sum y\right)^{2}}}$

dengan $\mathrm{x}=$ data hujan MRR dan $\mathrm{y}=$ data hujan satelit TRMM 3B42. Korelasi antar 2 variabel akan bernilai kuat apabila nilai korelasi semakin mendekati 1 dan semakin tidak berkorelasi apabila berlaku sebaliknya. Sedangkan nilai RMSE dinyatakan dengan sebagai berikut:

$$
\mathrm{RMSE}=\sqrt{\frac{\sum_{i}^{n}\left(y_{i}-\hat{y}\right)}{n}}
$$

dengan $\mathrm{n}=$ jumlah data yang digunakan, $\mathrm{y}=$ data hujan MRR/satelit TRMM 3B42, dan $\hat{y}=$ nilai rata-rata dari series data $\mathrm{y}$.

\subsubsection{Model HBV}

Model ini dapat disebut bersifat semidistributed. Bersifat distributed ditentukan dengan masukan data input pada level sub-basin dan bersifat lumped dengan menyeragamkan proses routingnya. Pada pemodelan kali ini dikarenakan keterbatasan data input maka akan digunakan model yang bersifat lumped. Pada umumnya model ini memiliki rumus water balance sebagai berikut [4] :

$$
\mathrm{P}-\mathrm{E}-\mathrm{Q}=\frac{d}{d t}[\mathrm{SP}+\mathrm{SM}+\mathrm{UZ}+\mathrm{LZ}+\mathrm{L}]
$$


dengan $\mathrm{P}=$ curah hujan, $\mathrm{E}=$ nilai evaporasi, $\mathrm{Q}$ $=$ debit limpasan, $\mathrm{SP}=$ snow pack, $\mathrm{SM}=$ soil moisture, $\mathrm{UZ}=$ upper zone, $\mathrm{LZ}=$ lower zone , dan $\mathrm{L}=$ lake volume.

Model ini terdiri dari bermacam-macam routing salju/hujan, air tanah, evapotranspirrasi, dan air bumi dengan 3 persamaan linier reservoir dan channel routing. Untuk daerah tropis yang tidak mengalami curahan berupa salju, HBV membagi lapisan tanah menjadi 3 bagian dan 1 channel routing berdasarkan respon permukaan tanah terhadap hujan yang turun. Empat lapisan tersebut adalah sebagai berikut: X1 (Soil Moisture Storage), X2 (Upper Storage), X3 (Lower Storage/Ground Water) dan X4 (Aliran air sungai). Model ini terdiri dari subrutin untuk interpolasi meteorologi, akumulasi dan lelehan salju, estimasi evapotranspirasi, prosedur perhitungan kelembaban tanah, rutinitas untuk pembangkitan limpasan dan terakhir prosedur pembuatan rute sederhana antara cekungan dan danau.

Beberapa parameter model dan estimasi evapotranpirasi potensial sebagai input berhubungan dengan debit aliran melalui sejumlah parameter dan konsep persamaan seperti yang digambarkan dalam gambar 2 . Parameter model dan variabel dipergunakan sebagai verifikasi dan validasi seperti: maximum soil moisture storage $(\mathrm{FC})=200$, limit for potential evaporation $(\mathrm{LP})=100$, beta coefficient $(\beta)=1$, percolation rate $(\mathrm{PERC})=1$, dan alfa $=1$, adalah merupakan recession parameter [6][7].

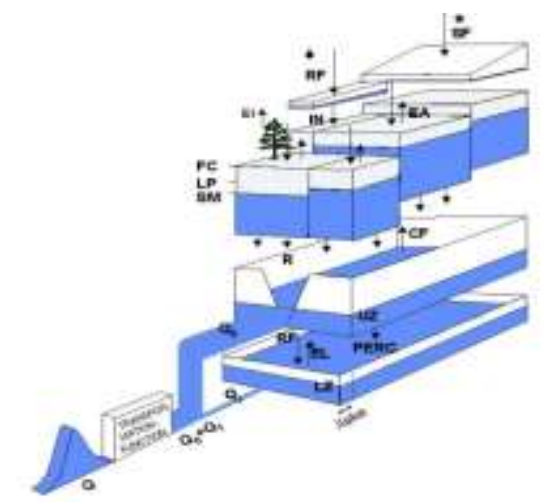

Gambar 2. Skema Struktur HBV Sumber : IHMS Manual

\subsubsection{Kalibrasi Pemodelan Hidrologi}

Untuk mengetahui seberapa baik model HBV dapat memodelkan DAS yang ditinjau maka diperlukan beberapa parameter ukur. Dalam penelitian ini digunakan diantaranya adalah nilai koefisien determinasi dan NashSutcliffe. Nilai koefisien Nash dan koefisien determinasi dapat dijabarkan sebagai berikut (Nash, 1970):

$$
\begin{aligned}
& \mathrm{NSE}=1-\frac{\sum\left(Q_{s i m}-Q_{o b s}\right)^{2}}{\sum\left(Q_{o b s}-\overline{Q_{o b s}}\right)^{2}} \\
& \mathrm{R}^{2}=\frac{\left(\sum\left(Q_{o b s}-\overline{Q_{o b s}}\right)-\left(Q_{s i m}-\overline{Q_{s l m}}\right)\right)^{2}}{\sum\left(Q_{o b s}-\overline{Q_{o b s}}\right)^{2} \sum\left(Q_{s i m}-\overline{Q_{s i m}}\right)^{2}}
\end{aligned}
$$
observasi.

Dengan $\mathrm{Q}_{\text {sim }}=$ debit simulasi, $\mathrm{Q}_{\mathrm{obs}}=$ debit

\section{HASIL DAN PEMBAHASAN}

\subsection{Analisa Data Hujan}

DAS Bedadung memiliki karakteristik pola hujan monsoon yang ditandai dengan tingginya curah hujan pada awal tahun dan akhir tahun serta sangat rendah pada pertengahan tahun. Dapat dilihat pada gambar 3 bahwa curah hujan tertinggi sering terjadi pada bulan Desember dengan hujan berlangsung dari bulan November hingga April. Dalam penelitian ini digunakan 14 pos hujan titik yang tersebar normal di DAS Bedadung. Stasiun-stasiun ini diantaranya adalah St. Tegal Batu, St. Dam Arjasa, St. Dam Karang Anom, St. Dam Klatakan, St. Dam Langkap, St. Dam Makam, St. Dam Pecoro, St. Dam Pono, St. Dam Semanggir, St. Dam Sembah, St. Dam Tugusari, St. Dam Kopang, St. Rambipuji, dan St. Rawatamtu. Sebelum data dapat diolah lebih lanjut perlu dianalisa lebih lanjut bahwa data yang dimiliki bersifat konsisten. Dapat dilihat pada Tabel 2 yang menunjukkan hasil uji RAPS pada keseluruhan data curah hujan MRR berada pada batas konsisten.

Tabel 2. Hasil Uji RAPS

\begin{tabular}{lccl}
\hline $\begin{array}{c}\text { Nama } \\
\text { Stasiun } \\
\text { Hujan } \\
\text { MRR }\end{array}$ & $\begin{array}{c}\text { Nilai } \\
\mathbf{Q} / \sqrt{n}\end{array}$ & $\begin{array}{c}\text { Nilai } \\
\mathbf{R} / \sqrt{n}\end{array}$ & $\begin{array}{c}\text { Keteranga } \\
\mathbf{n}\end{array}$ \\
\hline Arjasa & 0,7247 & 0,8869 & Konsisten \\
Karang & 0,7337 & 0,8060 & Konsisten \\
Anom & 0,6868 & 0,7331 & Konsisten \\
Klatakan & 0,7355 & 1,0053 & Konsisten \\
Kopang & 0,7445 & 0,8174 & Konsisten \\
Langkap & 0,
\end{tabular}




\begin{tabular}{lccl}
\hline $\begin{array}{c}\text { Nama } \\
\text { Hujan } \\
\text { MRR }\end{array}$ & $\mathbf{Q} / \sqrt{n}$ & $\mathbf{R} / \sqrt{n}$ & $\begin{array}{c}\text { Neteranga } \\
\mathbf{n}\end{array}$ \\
\hline Makam & 0,3968 & 0,5767 & Konsisten \\
Pecoro & 0,5639 & 0,6392 & Konsisten \\
Pono & 0,5938 & 0,7664 & Konsisten \\
Rambipuji & 0,4544 & 0,8771 & Konsisten \\
Rawatamtu & 0,5670 & 0,8493 & Konsisten \\
Semanggir & 0,8034 & 0,8034 & Konsisten \\
Sembah & 0,7612 & 1,2245 & Konsisten \\
Tegal Batu & 1,2313 & 1,2313 & Konsisten \\
Tugusari & 0,8353 & 0,8353 & Konsisten \\
\hline
\end{tabular}

Pada uji korelasi dalam penelitian ini menggunakan komparasi data dengan skala basin, yang berarti dalam satu grid data TRMM 3B42 akan mencakup beberapa stasiun hujan MRR yang sudah terbobot terhadap luas total DAS. Pembobotan pada setiap stasiun hujan menggunakan metode polygon thiessen, hal ini diharapkan data dapat mewakili setiap area di DAS Bedadung.

Gambar 4 menunjukkan gradient yang terbentuk pada scatter plot antara curah hujan satelit TRMM 3B42 (sumbu x) dan data hujan MRR (sumbu y).. Selanjutnya dilakukan analisis statistik untuk mengetahui hubungan dari kedua data tersebut. Perbandingan hubungan dari kedua data tersebut menunjukkan nilai korelasi sedang. Nilai R antara kedua data bernilai 0,49 dengan nilai RMSE bernilai sebesar 6,23. Dengan nilai tesebut dapat ditarik kesimpulan bahwa hubungan antara kedua data bernilai sedang. Dari perbandingan nilai curah hujan pada kedua jenis data pada Gambar 4 dapat disimpulkan bahwa nilai curah hujan pada data satelit TRMM 3B42 cenderung overestimate dari nilai data hujan observasi MRR.

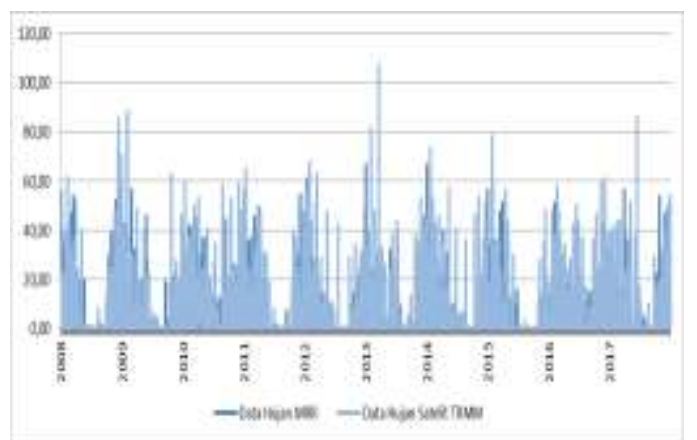

Gambar 3. Perbandingan Fluktasi Data Hujan MRR dan Satelit TRMM 3B42

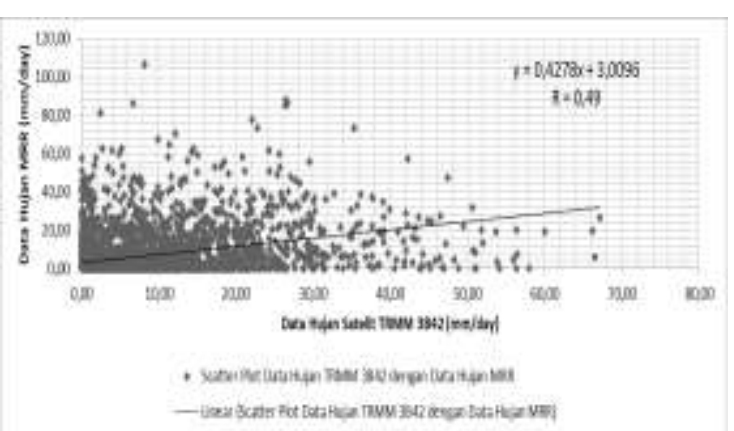

Gambar 4. Scatter Plot Data Hujan MRR dan Satelit TRMM 3B42

\subsection{Hasil Simulasi Model HBV}

Dalam pemodelan hidrologi menggunakan model HBV ini membandingkan ouput dari dua data input yang berbeda. Dari data 10 tahun yang digunakan akan dibagi menjadi 2 periode yaitu periode kalibrasi (20082012) dan periode validasi (2013-2017).

Dalam proses kalibrasi, pemodelan menghasilkan nilai nilai parameter model yang dapat dilihat pada Tabel 3. Parameter-parameter ini merupakan nilai representatif dari kondisi fisik dari DAS yang ditinjau.

Tabel 3. Parameter Kalibrasi

\begin{tabular}{ccc}
\hline \multirow{2}{*}{ Parameter } & \multicolumn{2}{c}{ Nilai } \\
\cline { 2 - 3 } & CH & CH TRMM \\
& MRR & 3B42 \\
\hline Alpha & 0,77 & 0,24 \\
K1 & 0.17 & 0.15 \\
K2 & 0.03 & 0.07 \\
MAXBAS & 1.65 & 1.1 \\
Cet & 1 & 0.37 \\
PART & 0.43 & 0.447 \\
DELAY & 1 & 21 \\
FC & 200 & 50 \\
LP & 1 & 1 \\
BETA & 1 & 1 \\
\hline
\end{tabular}

Dapat dilihat grafik pemodelan pada Gambar 5 bahwa pemodelan dengan input data hujan MRR pada periode kalibrasi menghasilkan nilai $\mathrm{R}^{2}$ dan NSE sebesar berturut-turut 0.7153 dan 0.7133 dengan mean error sebesar 89 (mm/tahun). Di samping itu pada periode validasi menghasilkan nilai $\mathrm{R}^{2}$ dan NSE sebesar berturut-turut 0,7014 dan 0,6977 dengan mean error sebesar 121 ( $\mathrm{mm} / \mathrm{tahun}$ ). Debit simulasi yang dihasilkan model ini telah 
mampu mengikuti fluktuasi debit observasi. Namun pada debit puncak, terutama debit yang lebih dari $40 \mathrm{~mm}$, model tidak mampu merepresentasikan besaran debit observasi dengan baik.

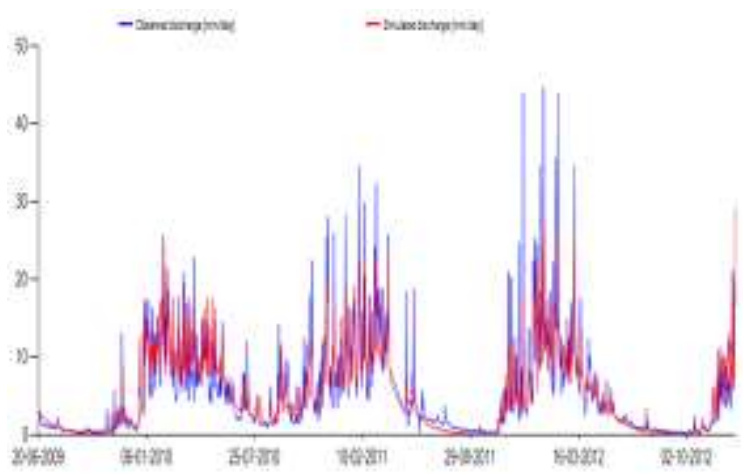

(a)

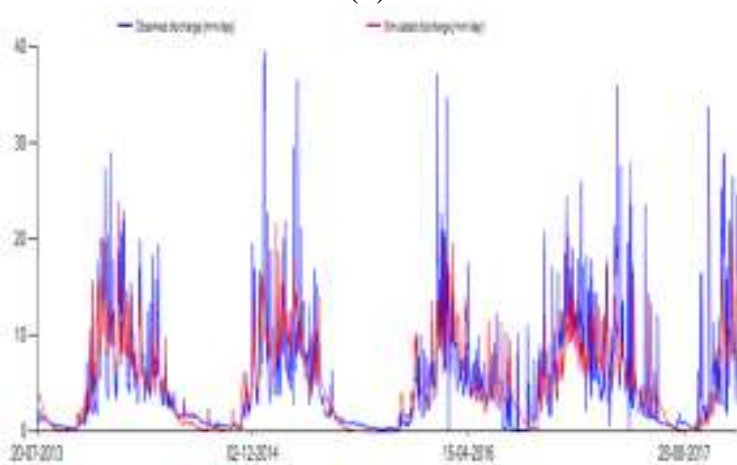

(b)

Gambar 5. Grafik Perbandingan Debit Observasi Dengan Debit Simulasi Mengggunakan Data Hujan MRR: (a) periode kalibrasi (2008-2012); (b) periode validasi (2013-2017)

Sedangkan untuk pemodelan dengan input data satelit TRMM 3B42 dapat dilihat grafiknya pada Gambar 6, periode kalibrasi menghasilkan nilai $\mathrm{R}^{2}$ dan NSE sebesar berturut-turut 0,574 dan 0,555 dengan mean error sebesar 305 (mm/tahun). Di sisi lain pada periode validasi model menghasilkan nilai $\mathrm{R}^{2}$ dan NSE sebesar berturut-turut 0,533 dan 0,478 dengan mean error sebesar 460 (mm/tahun). Dikarenakan nilai curah hujan satelit TRMM yang tidak mempunyai tingkat korelasi yang cukup tinggi dengan data curah hujan observasi tentu berdampak pada performa model. Dari hasil pemodelan tersebut dapat disimpulkan bahwa pemodelan menggunakan input data satelit TRMM 3B42 menghasilkan model hidrologi yang kurang dapat mewakiliki karakteristik DAS.

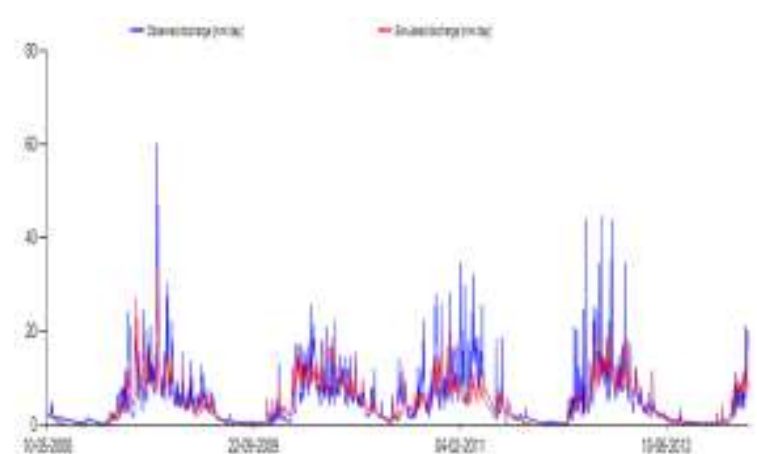

(a)

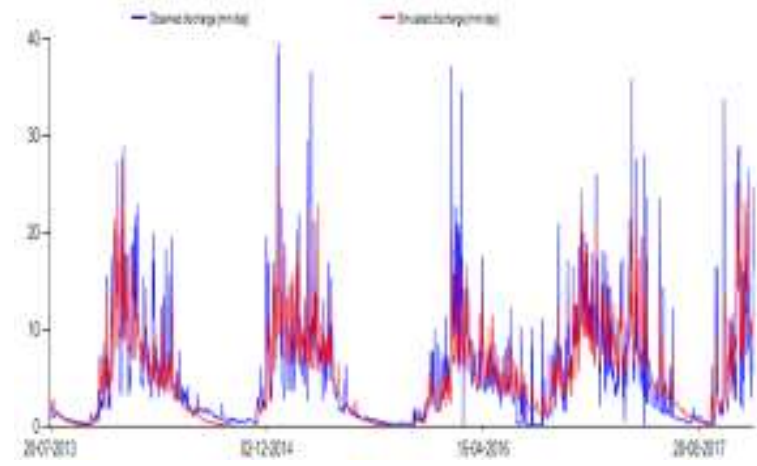

(b)

Gambar 6. Grafik Perbandingan Debit Observasi Dengan Debit Simulasi Menggunakan Data Hujan Satelit TRMM 3B42: (a) Periode Kalibrasi (2008-2012); (b) Periode Validasi (2013-2017)

Analisa lebih lanjut dilakukan dengan menghitung performa model dalam memodelkan debit -debit puncak dan debit minimum pada musim kering dan musim basah. Hal ini bertujuan untuk mengetahui kecenderungan model dalam memodelkan DAS Bedadung.

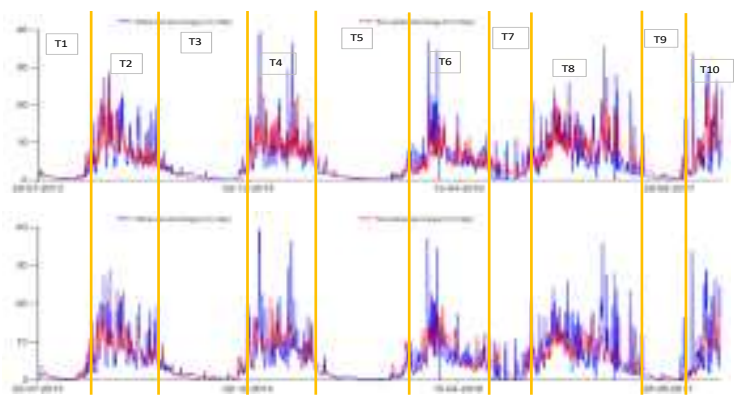

Gambar 7. Hasil Simulasi Model yang Dibandingkan Dengan Debit Observasi. Periode Waktu (T1T10) Digunakan Untuk Mengevaluasi Performa Model 
Tabel 2. Performa Model Pada Setiap Rentan Waktu yang Telah Ditentukan

\begin{tabular}{cccccccccccc}
\hline \multirow{2}{*}{ Keterangan } & \multicolumn{4}{c}{ Musim Basah } & \multicolumn{6}{c}{ Musim Kering } \\
\cline { 3 - 13 } & & T2 & T4 & T6 & T8 & T10 & T1 & T3 & T5 & T7 & T9 \\
\hline \multirow{2}{*}{ MRR } & NSE & 0,37 & 0,39 & 0,42 & 0,50 & 0,62 & 0,71 & 0,32 & 0,59 & 0,33 & 0,60 \\
& R2 & 0,73 & 0,56 & 0,29 & 0,93 & 0,93 & 0,61 & 0,29 & 0,27 & 0,19 & 0,44 \\
\multirow{2}{*}{ TRMM } & NSE & 0,37 & 0,22 & 0,23 & 0,03 & 0,09 & 0,54 & 0,40 & 0,37 & $-0,24$ & $-0,08$ \\
& R2 & 0,39 & 0,24 & 0,27 & 0,14 & 0,23 & 0,74 & 0,65 & 0,62 & 0,07 & 0,17 \\
\hline
\end{tabular}

Hasil dari pemodelan dibagi pada rentang waktu yang telah ditentukan yaitu dari T1 hingga T10 sesuai dengan pola fluktuasi debit yang menunjukkan musim basah dan musim kering. Pada setiap periode waktu yang telah ditentukan tersebut dianalisa menggunakan nilai $\mathrm{R}^{2}$ dan NSE dari produk luaran model sehingga dapat diketahui performa model pada tiap-tiap periode data. Pada tabel 2 performa paling baik ditunjukkan pada periode T8 dan T10 dengan input data MRR dengan nilai 0,93 . Sedangkan performa dengan hasil yang buruk ditujukkan pada periode $\mathrm{T} 7$ dan $\mathrm{T} 9$ dengan input data TRMM 3B42 yang menunjukkan nilai negatif pada koefisien nash sutcliffe. Secara umum, model ini mampu dengan baik memodelkan debit yang rendah hingga menengah, namun tidak dapat memodelkan debit debit puncak yang memiliki nilai tinggi. Dari analisa ini juga dapat disimpulkan bahwa secara keseluruhan input data hujan MRR lebih mampu mengikuti fluktuasi debit pada setiap periode waktu yang ditentukan daripada data hujan satelit TRMM 3B42.

\section{KESIMPULAN DAN SARAN}

Dua data dalam penelitian ini yaitu data hujan observasi dan data hujan satelit TRMM 3B42 setelah dilakukan uji korelasi menunjukkan nilai koefisien korelasi sebesar 0.49 yang menunjukkan bahwa korelasi data bernilai sedang. Hasil dari pemodelan hujan aliran menggunakan model HBV yang menggunkan dua data masukan yang berbeda yaitu data hujan MRR dan data satelit TRMM di DAS Bedadung dapat disimpulkan bahwa penggunaan data hujan MRR lebih dapat diandalkan daripada data satelit TRMM 3B42. Pada periode kalibrasi pemodelan yang menggunakan data stasiun hujan didapatkan nilai $\mathrm{R}^{2}$ dan NSE berturut turut sebesar 0,7153 dan 0,7133 dengan nilai Mean Error berkisar pada besaran $89 \mathrm{~mm} /$ tahun. Pada periode validasi didapatkan nilai $\mathrm{R}^{2}$ dan NSE sebesar berturut turut 0,7014 dan 0,6977 dengan nilai Mean Error berkisar pada besaran 121 $\mathrm{mm} /$ tahun.

Sedangkan kalibrasi pemodelan yang menggunakan data satelit TRMM 3B42 didapatkan nilai $\mathrm{R}^{2}$ dan NSE berturut turut sebesar 0,5741 dan 0,5550 dengan nilai Mean Error berkisar pada besaran $305 \mathrm{~mm} / \mathrm{tahun}$. Pada periode validasi didapatkan nilai $\mathrm{R}^{2}$ dan NSE sebesar berturut turut 0,5334 dan 0,4785 dengan nilai Mean Error berkisar pada besaran $460 \mathrm{~mm} /$ tahun.

Dalam model ini debit Dari hasil penelitian ini dapat disimpulkan bahwa model ini belum bisa merepresentasikan debit puncak pada DAS Bedadung. Perbaikan masukan data seperti data curah hujan dan data debit serta proses kalibrasi pada struktur model tertentu secara maksimal diperlukan agar model mencapai debit puncak.

\section{DAFTAR PUSTAKA}

[1] Liu, Z. 2015. Comparison of precipitation estimates between Version 7 3-hourly TRMM Multi-Satellite Precipitation Analysis (TMPA) near-real-time and research products. Atmospheric Research, 153, 119-133.

[2] Mamenun, M., Pawitan, H., \& Sopaheluwakan, A. 2014. Validasi dan koreksi data satelit trmm pada tiga pola hujan di indonesia. Jurnal Meteorologi dan Geofisika, 15(1)

[3] Pawitan, H., 2004. Perubahan penggunaan lahan dan pengaruhnya terhadap hidrologi Daerah Aliran Sungai. Laboratorium Hidrometeorologi FMIPA IPB, Bogor.

[4] Bergstrom, S., 1992, The HBV model its structure and applications, SMHI Report Hydrology., RH No. 4. Swedish Meteorological and Hydrological Institute, NorrkoÈ ping, Sweden 
[5] Lindstrom, G., B. Johansson, M. Persson, M. Gardelin., S. Bergstrom. 1997. Development and Test of The Distributed HBV-96 Hydrological Model. Swedish Meteorological and Hydrological Institute. Jurnal Hidrologi. 201(1997) 272-288.

[6] Sipayung, S.B., dan Nani C. 2010. Analisis Hubungan Curah Hujan dan Limpasan dengan di DAS Citarum Hulu Menggunakan Model
$H B V$. Prosiding Seminar Penerbangan dan Antariksa 2010. 15 November 2010. Pusfatsatklim. Hal 266-272.

[7] Sipayung, S.B. dan Nani C. 2012. Aplikasi Model HBV (Hydrologiska Byrans Vattenbalansavdelning) Berbasis Satelit di DAS Musi (Sumatra Selatan). Atmosfer Indonesia: Sains, Teknologi, dan Aplikasinya. Hal 48-61. 